\title{
A EXPERIÊNCIA INDÍGENA MEXICANA PLURALISMO JURÍDICO: DIRIETO CRÍTICO E A MARGEM DO SISTEMA ${ }^{1}$
}

Jesús Antonio de la Torre Rangel ${ }^{2}$

\begin{tabular}{|c|c|}
\hline RESUMO & ABSTRACT \\
\hline $\begin{array}{l}\text { Através da análise das manifestações produzidas pelos } \\
\text { povos e comunidades indígenas, nos últimos anos, no } \\
\text { México, o presente artigo busca entender e valorar este } \\
\text { pluralismo jurídico, esta jurisdição alternativa, desde } \\
\text { uma perspectiva crítica. Fará um breve relato quanto a } \\
\text { discussão sobre a existência de uma Crítica do Direito } \\
\text { no México, concluindo que o iusnaturalismo histórico } \\
\text { analógico propõem fazer a Crítica Jurídica desde o } \\
\text { pensamento da filosofia da libertação na América } \\
\text { Latina. Analisará,o desenvolvimento do movimento } \\
\text { Zapatista e a aplicação dos acordos de San Andrés no } \\
\text { país pelas comunidades e povos indígenas mexicanos, } \\
\text { produção de um Direito à margem do Estado. }\end{array}$ & $\begin{array}{l}\text { Through the analysis of the manifestations produced } \\
\text { by indigenous peoples and communities, in recent } \\
\text { years, in Mexico, this article seeks to understand and } \\
\text { assess this legal pluralism, this alternative jurisdiction, } \\
\text { from a critical perspective. Will make a brief report on } \\
\text { the debate on the existence of a criticism of law in } \\
\text { Mexico, concluding that the analog history } \\
\text { iusnaturalism propose making Legal criticism since the } \\
\text { thought of the philosophy of liberation in Latin } \\
\text { America. Analyse the development of the Zapatista } \\
\text { movement and the implementation of the agreements } \\
\text { of San Andrés in the country by the communities and } \\
\text { indigenous peoples in Mexico, production of a right } \\
\text { outside the State. }\end{array}$ \\
\hline Palavras-chave: Pluralismo jurídico, direito crítico. & Key-words: Legal pluralism, critical law. \\
\hline
\end{tabular}

\section{Introdução}

Salvo o movimento cidadão de resistência à violência, encabeçado pelo poeta Javier Sicilia denominado Movimento pela Paz com Justiça e Dignidade, nascido a princípios de abril de 2011, em México, nos últimos anos, os movimentos sociais mais importantes há sido produzidos por povos e comunidades indígenas.

Esta nova experiência indígena mexicana há gerado um pluralismo jurídico como Direito crítico e à margem do sistema

Para entender e valorar esse pluralismo jurídico, essa jurisdição alternativa, parto desde uma perspectiva crítica do Direito

\section{Iusnaturalismo Histórico Analógico e Crítica Jurídica.}

\footnotetext{
Texto traduzido do original em espanhol por Alexandrina Benjamin Estevão de Farias (alexandrinabenjamin@yahoo.com.br ) e Rogério Fernandes Rocha (rogerioarueira@hotmail.com ), graduandos em direito pela Faculdade de Direito da UFG.

${ }^{2}$ Professor da Universidade Autônoma do México. beastvtr@prodigy.net.mx
} 
Em janeiro de 2011, na Cidade Universitária (UNAM) da Cidade do México, celebramos um colóquio sobre a Crítica Jurídica no México. Conversamos tentando responder, entre outras, a estas duas perguntas: O que é a Crítica Jurídica? e Existe no México a Crítica Jurídica? Continuamos o diálogo durante a V Conferência Latino-americana de Crítica Jurídica, na Cidade de La Plata, Argentina, em outubro desse mesmo ano.

Com relação à primeira pergunta, me atrevi a responder, em termos muito gerais, que a Crítica Jurídica é o modo de entender o Direito de maneira não dogmática, não formal, não à maneira como se há transmitido de geração em geração no Ocidente desde quase dois séculos, e na América Latina desde um século e meio, seguindo os postulados da Escola da Exegese; tradição teórica na qual são formados os advogados, ainda que não se lhe mencione nem se cite aos autores, senão pela maneira legalista de se ensinar o Direito.

A Crítica do Direito, em seus postulados positivos, constitui um modo de entender a juridicidade, como uma produção social complexa; e um modo teórico de questionar a injustiça que essa juridicidade reproduz em sua pretensão legitimadora da desordem estabelecida como dizia Mourier ${ }^{3}$.

Com relação â questão plantada acerca de si existe Crítica Jurídica no México minha resposta foi afirmativa. Agregando que essa Crítica Jurídica se havia produzido, sobre tudo, desde duas tradições: o marxismo e o pensamento de libertação. Oscar Correas e seus discípulos pertencem à primeira e na segunda nós inserimos Alejandro Rosillo e eu. Em esse colóquio mencionarei uma terceira postura crítica, à Tradiçao Hispanoamaricana de Direitos Humanos, que está em intima relação com o pensamento de libertação.

Os autores que temos seguido para fazer Crítica Jurídica desde o pensamento de libertação, tem sido, sobre tudo, Ignacio Ellacuria com sua proposta de Filosofia da Realidade Histórica, e a Enrique Dussel utilizando as categorias de sua Filosofia da Libertaçao.

Seguindo estas linhas teóricas e incluindo a hermenêutica analógica de Mauricio Beuchot, propus uma visão crítica do Direito que denominei iusnaturalismo histórico analógico ${ }^{4}$.

33

Cfr. Emmanuel Mounier, Manifesto ao Serviço do Personalismo, Ed. Taurus, Madrid, 1972.

Cfr. Jesús Antonio de la Torre Rangel, Iusnaturalismo Histórico Analógico, Ed. Porrúa, México, 2011. 
Falamos de iusnaturalismo porque sustentamos que a justiça, o bem comum e os direitos humanos, postulados por essa tradição iusfilosófica, não são somente valores que as leis devam conseguir, o que é desejável alcancem; senão o sentido más profundo do Direito, são parte da juridicidade. Mas dizemos iusnaturalismo histórico, porque essa justiça, esse bem comum e esses direitos humanos, são negados freqüentemente na realidade; ante isso, não nos conformamos, nossa visão jurídica não se mantêm na afirmação teórica dessa justiça, desse bem comum e desses direitos humanos; senão que pretendemos que se façam história, se produzam na realidade histórica, se encamem na vida dos seres humanos. A totalidade jurídica instrumental fetichizada (normas, formas, procedimentos), legitima e reforçada ao poder econômico-político, que aliena a pessoas e comunidades; por isso pretendemos uma visão jurídica desde a exterioridade, desde as vitimas do sistema totalizado jurisdificado, e afirmamos o processo histórico até a justiça, o bem comum e os direitos humanos. Ante a legalidade da injustiça, oporemos os processos históricos de libertação que buscam uma legalidade justa e umas relações sociais equitativas.

A justiça e os direitos humanos, expressões humanas do Direito, os entendamos em seu conteúdo fundamental em quanto que portadores de condições materiais de vida. Por isso propusemos como campo hermenêutico com relação ao Direito, essa terrível realidade "da morte injusta e prematura" dos pobres, como disse Gustavo Gutiérrez ${ }^{5}$, porque é o que o jurídico deve reparar em sua aplicação concreta; quero dizer que o Direito tem seu pleno sentido, quando ao aplicar-lo se assume a realidade da morte injusta e prematura dos pobres e se buscam as condições matérias de vida que evitem essa morte.

Por ele, a justiça e os direitos devem entender-se desde o outro, desde o oprimido, desde o negado, desde o pobre, desde das vitimas. O sentido profundo do jurídico, desde a raiz, vem dado pelo outro, qualquer pessoa que exige respeito de sua dignidade, mas analogamente, analécticamente, desde o empobrecimento, o que padece injustiça, o negado em seus direitos, o pobre, a vitima de todo sistema totalizado. 


\section{A EXPERIÊNCIA INDÍGENA MEXICANA}

16

Este é o modo que o iusnaturalismo histórico analógico propõem para fazer a Crítica Jurídica desde o pensamento de libertação na América Latina.

Desde esta visão crítica do Direito, aceitamos o Direito Alternativo em sua expressão de Pluralismo Jurídico.

E é desde esta perspectiva que analisamos a experiência do pluralismo jurídico de povos e comunidades indígenas no México.

\section{Sobre o Pluralismo Jurídico.}

A concepção do Direito na modernidade é unívoca. O Direito tem um só sentido, responde a uma única realidade: o Direito é a Lei. Assim, Lei é igual a Direito: e Direito é igual a Lei. E a lei tem como fonte exclusiva de origem ao Estado. Dessa maneira, o Direito está constituído por um conjunto de normas estabelecidas pelo Estado para que rejam a sociedade, e se lhe chama Lei. A Lei constitui a base do sistema jurídico.

Disse Paolo Grossi que, com o advento da concepção moderna do Direito, o velho pluralismo é substituído por um rígido monismo, de tal modo que o "drama do mundo moderno consistirá na absorção de todo o direito pela lei, em sua identificação com a lei”6.

Reconhecemos que o Direito é Lei, conjunto de normas, mas não somente é isso, constitui também direitos subjetivos, faculdades das pessoas e dos grupos sócias sobre o seu, e ademais, Direito é as coisa e/ou condutas devidas aos outros, isto é o justo objetivo, como concretização da justiça. Por outro lado, o Estado não é a única fonte de produção do jurídico. Os usos e costumes, os princípios gerais do Direito, a realidade mesma, natureza e historia, do ser humano e das coisas produz juridicidade. O Direito também nasce do povo; das relações inter-humanas, das lutas e reivindicações de diversos coletivos.

O pluralismo jurídico se separa da teoria univocista da modernidade, faz um rompimento epistemológico. Aceita a diversidade, o plural, não de maneira equivoca: não o todo se vale; não o todo é Direito; senão com uma racionalidade analógica, que aceita o

6

Paolo Grossi, Mitología Jurídica da Modernidade, Ed. Trotta, Madrid, 2003, p. 36. 
diverso, o distinto, mas sem perder o essencial da juridicidade, o que lhe dá sentido em última instancia o que lhe permite ser Direito: a justiça.

Aceito, então, como pluralismo jurídico aquele que implica um projeto emancipador, uma práxis de libertação. Isto é, "um projeto jurídico resultante do processo de práticas sociais insurgentes, motivadas para a satisfação de necessidades essenciais." ${ }^{7}$.

O ser humano é a raiz de todo Direito, a fonte originária de toda juridicidade; e, por tanto, de algum modo, os direitos humanos são necessidades juridificadas. De modo similar, Wolkmer nos explica como se produz o Direito, como se desenvolve na própria sociedade, e "ressalta a importância de buscar formas plurais de fundamentação para a instancia da juridicidade, contemplando uma construção comunitária cristalizada na plena realização existencial, material e cultural do ser humano." ${ }^{8}$.

O pluralismo jurídico assim gerado, em palavras do próprio professor Wolkmer, "é um pluralismo comunitário-participativo, cuja fonte de Direito é o próprio ser humano projetado em suas ações coletivas que incorpora a juridicidade concreta e a liberdade emancipada." 9 . Assim se tem produzido a juridicidade à margem do sistema na experiência indígena mexicana nos últimos anos.

\section{Alguns frutos da Revolução Zapatista}

A insurreição do Exercito Zapatista de Libertação Nacional (EZLN), de primeiro de janeiro de 1994, deixou ao descoberto muitas deficiências do nosso sistema social, político e econômico, e inclusive revelou uma carência ética fundamental da sociedade mexicana

\section{7}

Antônio Carlos Wolkmer, "Pluralismo Jurídico: Novo marco emancipatorio em América Latina", em Jesús Antonio de la Torre Rangel (coordenador) Pluralismo Jurídico, Teoria y Experiências, Facultade de Direito da Universidade Autônoma de San Luis Potosí e Centro de Estudos Jurídicos y Sociais P. Enrique Gutiérrez, San Luis Potosí, 2007, p. 26.

88

Antônio Carlos Wolkmer, Pluralismo Jurídico. Fundamentos de uma nova cultura do Direito, Ed. MAD, Sevilla, 2006, p. 143.

99

Idem, p. 151. 


\section{A EXPERIÊNCIA INDÍGENA MEXICANA}

18

dominante, a criola e mestiça, para relacionar-se com o outro, com o índio. Desde o ponto de vista jurídico, podemos dizer que o movimento insurrecional de Chiapas, ao questionar o conjunto da organização de nossa convivência, implicou um forte terremoto de toda a juridicidade.

A dura realidade do índio mexicano em geral, constitui a mesma negação do direito à vida digna, expressão que bem pode sintetizar todos os direitos humanos. Isso em virtude de que as condições de vida - ou terá que dizer de morte? - a que tem sido levados os povos índios mexicanos, soa em si mesma negadoras do que Joaquín Herrera chama o direito a ter direito, "como ' conteúdo essencial' dos direitos humanos", já que "constitui o núcleo de valor da dignidade humana" ${ }^{\prime \prime}$.

Leva razão Herrera Flores quando diz que esse "conteúdo essencial" dos direitos humanos que é o direito de ter direito, "necessita para sua colocação em prática essa tripla condição de 'vida', 'liberdade', 'igualdade'. Os direitos humanos serão, pois, as normas e regras que institucionalizam juridicamente a 'justa existência' dos seres humanos de ser sujeitos de direitos, de que se estabeleçam e desenvolvam - por parte de todos - as condições que possibilitam sua atuação como ser racional - vida e liberdade - e que lhes facilitam a colocação em prática dos direito que lhes correspondem como seres humanos - igualdade, solidariedade e interdependência."11.

As demandas zapatistas, ao juridicionar-se, são reclamos que implicam desde as condições necessárias para o direito de ter direito até desenvolver-se em um largo catálogo de direitos. As necessidades expressadas se jurisdicionam, se traduzem ao mundo jurídico, e constituem assim exigência de reconhecimento e respeito de direitos. 
Vejamos os pontos das demandas ${ }^{12}$ apresentados pela representação do Exército Zapatista de Libertação Nacional na mesa de diálogo nas chamada Jornadas pela paz e da reconciliação em Chiapas, celebrada em São Critóval das Casa a fins de fevereiro e aos primeiros dias de março de 1994.

15. Já não queremos seguir sendo objeto de discriminação e desprezo que temos vindo sofrendo desde sempre os indígenas.

14. Que se respeitem nossos direito e dignidade como povos indígenas tomando em conta nossa cultura e tradição.

Em especial estas demandas décima quinta e décima quarta são básicas, já que se referem às condições para exercer $o$ direito de ter direito; e são radicais, ademais, porque sua atenção leva a corrigir nossa relação social originária, vai à raiz ética de nossa relação com o outro, com o índio, que implica primeiro não negar-lo mas reconhecer-lo. A raiz de todo direito é o reconhecimento da dignidade do outro como outro. A formulação dessas demandas é muito simples, mas de radicais repercussões para a ética, o Direito e a sociedade.

Os outros direitos reclamados, expressados como demandas para satisfazer suas necessidades, e que implicam necessariamente a atenção das demandas décima quinta e décima quarta, todos levam a esse direito que é síntese de todos os direitos a uma vida digna.

O ELLN reclamava um regime autônomo para os povos índios; a demanda 4 está formulada assim:

Novo pacto entre os integrantes da federação que acabe com o centralismo e que permita a regiões, comunidades indígenas e municípios autogovernar-se com autonomia política, econômica e cultural. ${ }^{13}$

\footnotetext{
112
}

“As demandas Zapatistas”, em El Financiero, México, 3 de março de 1994, p. 46. Também em "Perfil de La Jornada", em La Jornada, México, 3 de março de 1994, p. II.

“As Demandas... Op. Cit. 


\section{A EXPERIÊNCIA INDÍGENA MEXICANA}

20

E a demanda 16:

Como povo indígena que somos que nos deixem organizarmos e governarmos com autonomia própria, porque já não queremos ser submetidos à vontade dos poderosos nacionais e estrangeiros. ${ }^{14}$

A muito rica experiência indígena mexicana dos últimos anos, em boa medida, é fruto da insurreição do Exercito Zapatista de Libertação Nacional. A revista Conspiratio dedica seu número 07 a responder o questionamento acerca de si hoje é possível a revolução; os colaboradores argumentam fundamentando diversas opiniões. Gustavo Esteva considera que há uma revolução que está em marcha, e conversa com Conspiratio, em estes termos:

Conspiratio: A partir do exemplo e iniciativa do EZLN, tua proposta política é a da revolução dos âmbitos de comunidade, que são próprios do México profundo. Esta, que se há dado em chamar a primeira revolução do século XXI, seria uma revolução não pelo poder mas pela convivência. Acredita realmente que esta revolução segue em frente? Quais são seus desafios mais importantes? Ou, se não é assim, onde considera que se há parado?

Gustavo Esteva: O EZLN há sinalizado repetidamente que não pretende impor um modo específico de sociedade a todos os mexicanos. Insiste em que são estes os que devem ser capazes de expressar democraticamente sua vontade para criar a sociedade que desejam, mas não através de estruturas de representação como as atuais senão em forma direta.

Desde meu ponto de vista, a revolução se tem estado tecendo desde a base social, nos mais diversos âmbitos, se ocupa primordialmente da autonomia, em espaços nos que a gente possa decidir por si mesma. Em esses espaços, as normas de convivência, definidas pela própria gente, estariam mais além da

Ibidem 
sociedade econômica, capitalista ou socialista, e poderiam caracterizar-se com o termo, que Iván Illich renovou, de "convivencialidade". ${ }^{15}$

Ameglio pensa também que o aporte da revolução que se está fazendo, tem a ver com a autonomia das comunidades, e o considera como um fruto da ocupação política do zapatismos. Ao recordar que o 17 de novembro de 1983, três indígenas e três mestiços estabeleceram o primeiro acampamento do EZLN, agrega que os "urbanos" que chegaram para fazer uma guerrilha e lutar por "um governo socialista", "foram 'derrotados' pela experiência histórica e cultural da luta indígena", e

Graças a esta ruptura epistêmica, moral e intelectual nasceu algo original: um exército indígena que, sem deixar de ser-lo, luta em forma civil e pacifica desde quase 17 anos por construir um principio de ordem social não capitalista chamados por eles 'autonomia'. ${ }^{16}$

A autonomia reclamada, produzida dia a dia, e vivida sem permissão, é quizas o fruto mais importante da revolução do EZLN. Fruto não somente para suas comunidades base, mas também para muitas comunidades ao longo e amplo de todo México.

\section{Alguns ensinamentos de Fanón}

Escreve Frantz Fanon estas palavras que se aplica aos povos indígenas mexicanos neocolonizados:

Para o povo colonizado, o valor mais essencial, por ser o mais concreto, é primordialmente a terra: a terra que deve assegurar o pão e, por suposto, a

15

Gustavo Esteva, “A revoluçao que está em marcha”, Conversa com Conspiratio, em Conspiratio 07, México, setembro-outubro, 2010, p. 45.

116

Pietro Ameglio, "Pensar em Voz Alta. 27 y 17: gênesis e grito de dignidade zapatista", em Conspiratio 04, México, março-abril, 2010, p. 14. 


\section{A EXPERIENNCIA INDÍGENA MEXICANA}

22

dignidade. Mas essa dignidade não tem nada que ver com a dignidade da "pessoa humana”. Essa pessoa humana ideal, jamais há ouvido falar dela. ${ }^{17}$

Isto traz a minha memória àquilo que me escreveu faz alguns anos Arturo Paoli, sempre com sua provocação religiosa, prevenindo-me frente às abstrações sobre a dignidade da pessoa: "Pensa sempre em um camponês, em um índio otomí, que virtualmente, são filhos de Deus, são maiores que todo o firmamento diria Pascal, mas é como se a sociedade os tivessem cobertos de barro, moldados, reduzidos à impotência." 18

O levantamento do Exercito Zapatista de Libertação Nacional (EZLN), foi pela terra e pela dignidade. A terra que não somente dá sustento material, mas também permite o desenvolvimento da comunidade e a manutenção da identidade. A partir de então, povos e comunidades indígenas do México, seguem em sua luta pela terra, quando menos por conservar o que lhes sobra frente aos embates da reforma agrária de mercado que se tem implementado.

Essa dignidade se vai afirmando como sua proposta de valores culturais contra hegemônicos e com a produção de Direito como pluralismo jurídico.

$\mathrm{Na}$ resistência indígena atual, pela experiência de pluralismo jurídico vivida por povos e comunidade do México, a partir da insurreição do EZLN, se produziu a reconquista da dignidade, da reafirmação de valores e a reivindicação de direitos.

\section{Os Acordos de San Andrés: o verdadeiro Direito de povos e comunidades.}

Com motivo de levantamento do EZLN, e com fundamento na Lai para o Diálogo, a Conciliaçao e para a Paz Digna em Chiapas, que tem por objeto precisamente o que enuncia seu título, começaram a desenvolver-se as mesas de diálogo de San Andrés Sacamch en entre o Exercito Zapatista de Libertaçao Nacional (EZLN) e o Governo Federal. E se bem o diálogo $1 \overline{17}$

Frantz Fanon, Os condenados da terra, Ed. Fondo de Cultura Económica, México, 2007, págs. 38-39.

118

Carta de Arturo Paoli, fechada en la comunidade de Bojö, no Estado Lara, em Venezuela, 28 de abril de 1975 (Arquivo pessoal). 
se interrompeu, a primeira mesa, sobre Direitos e Cultura Indígena, se concluiu e produziu vários documentos firmados em 16 de fevereiro de 1996.

O primeiro documento acordado, consentido pelas partes, é o Pronunciamento conjunto que o Governo Federal e o EZLN enviarão às instrancias de debate e decisão nacional. Sua primeira parte se denomina "Contexto da nova relação"; na mesma se reconhece " aos povos indígenas como novos sujeitos de direito"19 baseando-se em sua origem históricas, em suas demandas na natureza pluricultural da nação mexicana e no ordenado pelo Convenio 169 da Organização Internacional do Trabalho (OIT), assinado e ratificado pelo Estado Mexicano, e por tanto normativa obrigatória de acordo ao ordenado pelo artigo 133 constitucional. Este acordo é muito importante por seus alcances jurídicos, pois como sinaliza Cossio: “O sujeito histórico, social e político das reivindicações indígenas passou de ser um ente individual a um coletivo e, por tanto, a partir do último é como devem entender-se as negociações de San Andrés, seus resultados e as soluções jurídicas." ${ }^{20}$.

A segunda parte deste documento se titula " Compromissos do Governo Federal com os Povos Indígenas", e começa dizendo que "As responsabilidades que o Governo Federal assume como compromisso que o Estado Mexicano deve cumprir com os povos indígenas em sua nova relação são", e a continuação enuncia e estabelece o claro conteúdo dessas obrigações governamentais. São em número de oito e estão constituídas do seguinte teor:

1. Reconhecer aos povos indígenas na Constituição Geral, se trata de um compromisso que implica que "O Estado deve promover o reconhecimento, como garantia constitucional, do direito à livre determinação dos povos indígenas", o qual "se exercerá em um marco constitucional de autonomia assegurando a unidade nacional. Poderão, em

119

Cfr. Acordos sobre direitos e cultura indígena, Ed. Frente Zapatista de Liberación Nacional, México, março de 1997, págs. 5

220

José Ramón Cossío D., “Análises Jurídico dos Acordos de San Andrés Larráinzar”, em Folhetos de Este País, Este País. Tendências e Opiniões Nº 86, México, maio, 1998, p. 5. 


\section{A EXPERIÊNCIA INDÍGENA MEXICANA}

24

conseqüência, decidir sua forma de governo interno e suas maneiras de organizar-se política, social, econômica e culturalmente." 21

2. Ampliar participação e representação políticas. O Estado cumprirá com esta obrigação impulsionando "câmbios jurídicos e legislativos que ampliem a participação e representação política local e nacional dos povos indígenas" e isto, entre outras coisas, deve levar "ao reconhecimento de direitos políticos, econômicos, sociais e culturais dos povos indígenas..."22

O compromisso 3, o escreveremos completo, por tratar-se de uma matéria estritamente jurídica:

3. Garantir acesso pleno à justiça. O Estado deve garantir o acesso pleno dos povos à jurisdição do estado Mexicano, com reconhecimento e respeito a especificidades culturais e os seus sistemas normativos internos, garantindo o pleno respeito aos direitos humanos. Promoverá que o direito positivo mexicano reconheça as autoridades, normas e procedimentos de resolução de conflitos internos aos povos e comunidades indígenas, para aplicar justiça sobre a base de seus sistemas normativos internos, e que mediante procedimentos simples, seus juízos e decisões sejam convalidados pelas autoridades jurisdicionais do Estado. ${ }^{23}$

Dos cinco compromissos restantes estabelecemos somente os enunciados: 4. Promover as manifestações culturais dos povos indígenas; 5. Assegurar educação e

\footnotetext{
221

Acordos, Op. Cit. p. 6.

222

Ibidem

223
}

Ibidem 
capacitação; 6. Garantir a satisfação de necessidades básicas; 7. Impulsionar a produção e o emprego; e 8. Proteger aos indígenas migrantes.

A Comissão de Concórdia e Pacificação (COCOPA), criada pela própria Lei para o Diálogo, a Conciliação e a Paz Digna em Chiapas, integrada por membros do Congresso da União, apresentou até os finais de 1996 à consideração do Exercito um projeto de reformas à Constituição Política dos Estados Unidos Mexicanos, na que se traduzia legalmente os acordos que sobre a autonomia dos povos indígenas havia chegado na primeira mesa de San Andrés. Foi até princípios de dezembro de 2000, que o Presidente da Republica Vicente Fox Quesada, submeteu ao Constituinte Permanente a postergada Iniciativa de Reforma Constitucional da COCOPA; mas se aprovaram umas reformas à Constituição em matéria indígena, distintas às da proposta. A Reforma constitucional se publicou no Diário Oficial em sua edição de 14 de agosto de 2001.

Os representantes e assessores do EZLN e do Congresso Nacional Indígenas repudiaram a Reforma Constitucional por considerar-la não somente insuficiente, senão também, em alguns aspectos, contraria aos interesses dos povos indígenas.

Ante isto: O que há sido dos Acordos de San Andrés Larráinzar ou Sacamch'en? Na atualidade, os Acordos de San Andrés, constituem letra morta? São simples referências anedótica que formou parte de um processo político? Vem a ser somente parte do grande acumulo de frustrações dos povos indígenas mexicanos?

Os Acordos de San Andrés estão vivos, mais vivos que nunca, e em certo sentido constituem juridicidade, são Direito. Não pertencem ao passado; são atuais na vida dos povos e comunidades indígenas.

Vejamos de que modo estão presentes e como é que são Direito. Me refiro a feitos concretos. Em outubro de 2005, em Pueblo Hidalgo, Guerrero, se celebrou o décimo aniversário de La Polícia Comunitária - primeiro organismo da Experiência Comunitária de Seguridade e Justiça da Montanha e Costa Chica de Guerrero-, e com esse motivo, os povos Me Phaa, Na Sayi, Nahuatl e Ñomdaa juntos com a Coordenadora Regional de Autoridades Comunitárias e o Comitê Executivo da Polícia Comunitária, fizeram pública a Declaração, a qual, entre outras coisas, diz: 
26

Se necessita enriquecer as experiências comunitárias orientadas a conhecer e colocar em prática os Acordos de San Andrés. Nosso sistema é produto de exercer a livre determinação dos povos e se fundamente nos Acordos de San Andrés; os quais devem seguir considerando em nossa região e ampliar-los a partir de nossas próprias experiências, luta e resistência. ${ }^{24}$

Com maior razão, uma das mesas de trabalho e reflexão que se celebraram em esse evento do décimo aniversário da Polícia Comunitária, tratou dos Acordos de San Andrés. E nessa Mesa 1, respondendo à pergunta "como posso criar a justiça e seguridade comunitária sem reconhecimento constitucional ao direito dos povos?", entre outras coisas se respondeu: "É importante aplicas os Acordos de San Andrés pela via dos feitos e isso seria a melhor maneira de respeitar-los...É fundamental dar a conhecer os Acordos de San Andrés através das próprias línguas maternas das comunidades, realizar oficinas para dar-los a conhecer e que seus integrantes se apropriem deles..."

Outro feito contundente. O XVI Encontro de União de Agentes da Pastoral Indígena (EAPI), celebrado de 13 à 16 de fevereiro de 2006, na Huasteca Potosina, na Paróquia de "São Miguel Arcanjo" de Tancanhuitz (canoa de flores amarelas), San Luis Potosí, com a participação de membros dos seguintes povos: : Nahuatl, Me'pha (Tlapanaco), Txeltal, Chol, Zoque, Chontal, Purepecha, Hñahñu, Nñathró, Ñnu'hei, Ñuh Sabi (Mixteco), Cuicateco, Mazahua, Queqchi, Ay', Ukjäyë (Mixe), Tenec, Ni'nguiva (Popoluca), Totonaco, Matlazinca, Amuzgo, Cha't', Ña'n (Chatino), Mazateco, Chinanteco, Xi'iuy (Pame), O'dame (Tepehuan) y Kaqchiquel (de Guatemala), teve como objetivo a tomada de consciência dos direitos que lhes correspondem aos povos indígenas. Em sua Mensagem Final se disse:

Muito nos alegra saber que os Acordos de San Andrés, ainda não se tornaram lei, se expressam de maneira substancial o que é nosso, pelo mesmo, os

22

Declaração do 10 Aniversario do Sistema de Seguridade, Justiça e Processo de Reeducação Comunitária, Povo Hidalgo, Guerrero a 15 de outubro de 2005. 
assumimos como norma fundamental de nossa vida comunitária, pois nossos direitos são mais que o que está escrito nas leis. ${ }^{25}$

Esta afirmação é produto do trabalhado e dito nas distintas mesas. Os Acordos de San Andrés constituem a base das relações jurídicas de povos e comunidades, de seu Direito. Tive oportunidade de participar dos trabalhos do EAPI - 2006, de tal modo que, como advogado e estudioso do Direito, fiquei impressionado da presença tão forte dos Acordos de San Andrés na juridicidade viva, objetiva, real, dos povos e comunidades indígenas.

Outrso exemplo a mais da vigência dos Acordos de San Andrés o constitui o Manifesto de Ostula, sem duvidas o documento mais importante produzido em 2009 pela luta dos povos indígenas mexicanos. O Manifesto de Ostula é fruto da XXV Assembléia plenária do Congresso Nacional Indígena, Regiao Centro - Pacífico, realizada em território indígena da costa Nahua de Michoacán; se deu 14 de junho de 2009 na Comunidade de Santa Maria de Ostula, Aquila; os e as representantes dos povos Nahua, Wixárika, Purepecha, Binniza, Hñahñuu, Coca, Tzeltal, Ñu Sabi e Rarámuri expressaram:

Reafirmamos nosso reconhecimento aos Acordos de San Andrés, como Lei Suprema e Constituição dos Povos Indígenas do México. ${ }^{26}$

Quiçá a melhor explicação deste feito, desta realidade jurídica de Direito que nasce do povo, a encontremos em alguns conceitos vertidos na $V$ Declaração da Selva Lacandona do Exercito Zapatista de Libertação Nacional, de 17 de julho de 1998, que considera que na reunião de San Andrés “a vontade de todos os povos índios...se fez coletiva..."27.

\footnotetext{
225

XVI Encontro E.A.P.I., Mensagem Final, Tancanhuitz, 16 de fevereiro de 2006.

226

Manifesto de Ostula, em Rebeldía 66, 2009, págs. 46-48.

$2 \quad 27$

EZLN, Documentos e Comunicados 4, Ed. Era, México, 2003, pág. 229.
} 
De tal modo, que os Acordos de San Andrés estão vivos na memória histórico-jurídica dos povos indígenas como uma "vontade coletiva" participante na reivindicação de sua autonomia, e também como recordação de uma traição, a das autoridades do Estado.

Ademais esses Acordos estão presentes como as normas básicas de sua organização interna e como critério jurídico inspiradores de sua juridicidade; são direito fundamentais de povos e comunidades.

\section{Municípios autônomos e Juntas de Bom Governo zapatistas.}

Depois da reforma Constitucional emitida pelo Congresso da Uniao atuando como órgão revisor da Constituição e da confirmação implícita da Reforma pela Suprema Corte de Justiça, os povos indígenas mexicanos não se deram por vencidos. Como disse Lópes Bárcenas "os zapatistas e grande parte do movimento indígena ...se regressaram a suas comunidades a exercer nos feitos o que o Estado lhes havia negado reconhecer em suas leis: o direito à autonomia." 28

$\mathrm{Na}$ zona de influencia zapatista funcionam municípios autônomos rebeldes conduzidos pelas próprias comunidades. Nestas experiências próprias de autogoverno, o EZLN não intervém. Se demarca o campo político administrativo que corresponde às autoridades municipais e o campo militar; os líderes militares do EZLN não podem ocupar cargos de autoridade nem em comunidades nem municípios.

Em agosto de 2003 as comunidades zapatistas anunciam a instauração das Juntas de Bom Governo "criadas com o fim de resistir o desequilíbrio no desenvolvimento dos municípios autônomos e das comunidades; para mediar nos conflitos que pudessem apresentar-se entre municípios autônomos e entre municípios governamentais; para atender as denuncias contra os Conselhos Autônomos por violações aos direitos humanos, protestos e

\footnotetext{
228

Francisco López Bárcenas, “O largo caminho das autonomias indígenas”, em La Jornada, México, 13 de agosto de 2003.
} 
inconformidades" 29 , y para outras tarefas de apoio e coordenação em relação aos próprios municípios autônomos.

As Juntas de Bom Governo estão constituídas por agrupações de municípios autônomos; suas autoridades são designadas pelos próprios municípios, dentre os municípios elegidos pela comunidade de base. ${ }^{30}$

Com as Juntas de Bom Governo nascem os Caracóis como espaço de encontro político e cultural.

Com data vinte e seis de fevereiro de 1994, o Exercito Zapatista de Libertaçao Nacional (EZLN) deu um comunicado que se conhece como mandar obedecendo, onde estabelece suas linhas fundamentais de filosofia política, sua concepção do exercício do poder y seu modo de entender a democracia. ${ }^{31}$

Os municípios autônomos rebeldes e as Juntas de Bom Governo têm essa filosofia política como base. Sua tendência, ao exercer o governo, é a de mandar obedecendo. Produzem outro direito, um direito alternativo, com uma racionalidade jurídica distinta à do direito dominante. ${ }^{32}$

\section{Experiência Comunitária de Seguridade, Não Divisão da Justiça e Reeducação da Montanha e Costa Chica de Guerrero.}

Gloria Muñoz Ramírez, EZLN: 20 e 10 ou fogo e a palavra, Ed. Revista Rebeldía y Jornada Ediciones, México, 2003, págs. 247 y 248.

$3 \quad 30$

Cfr. Oscar Correas, Direito Indígena Mexicano II, Ed. Coyoacan e Centro de Investigaçoes Interdisciplinarias em Ciencias e Humanidades, UNAM, México, 2009, p. 235.

331

EZLN Documentos e Comunicados 1, Ed. Era, México, 1995, págs. 175 y 176.

Veja-se uma interessante crítica do zapatismo às leis e ao "Estado no capitalismo": Sub-comandante Inssurgente Marcos, “Lutamos, lutaremos, venceremos”, em Rebeldía 43, junho, 2006, págs. 3-7. 


\section{A EXPERIÊNCIA INDÍGENA MEXICANA}

30

Este exercito comunitário de justiça indígena, se implementou em parte das regiões Montanha e Costa Chica do Estado de Guerrero. Os indígenas participantes são tlapanecos, mixtecos, nahuas e amuzgos.

Por outro lado vários dos municípios aos que pertencem as comunidades da Montanha e Costa Chica, são dos mais pobres do país. Quase noventa por cento das localidades indígenas da região estão catalogadas como de alta e muito alta marginalização; a desnutrição e a fome são somente os sintomas mais dolorosos de sua enorme pobreza. É uma zona também conflitiva por problemas de posse da terra, sendo freqüentes os pleitos agrários por diversas causa. ${ }^{33}$

A grande insegurança da região, provocada pelo funcionamento de grupos de delinqüentes que fizeram do assalto prática comum nos meios de comunicação entre as comunidades de El Rincón, San Luis Acatlan, Pueblo Hidalgo, Ayutla de los Libres, Tlaxcalixtlahuaca e Marquelia; ademais a freqüência do furto de gado, a onda de crimes e de violências sexuais praticadas até em menores de idade; essa insegurança, com o clima de terror que originava, unida a um sistema estatal de segurança e de não divisão da justiça corrupta e ineficaz, motivou a criação, primeiro, da Polícia Comunitária, e depois de toda uma experiência integral de segurança e administração da justiça, no que foi derivando.

A Polícia Comunitária tem sua origem nas comunidades organizadas, "é um movimento indígena". ${ }^{34}$ Ante a terrível insegurança da zona e a ineficiência e corrupção das instâncias de segurança e justiça do Estado, várias organizações regionais, como os cafezais União de Campos "Luz da Montanha" y a União Regional Campesina, as Paróquias, o Conselho Guerrerense 200 Anos de Resistência Indígena e o Centro Comunitário de Abundância chamado a Tríplice SSS, viram a necessidade de abordar o tema, e com este objeto se iniciam as assembléias comunitárias que tinham o propósito de colocar remédio a essa problemática. Em um princípio, se pensou que a solução estava no governo. De tal modo

33

Cfr. Diagnóstico da Diocese de Tlapa, elaborado pelo Conselho Pastoral da Diocese de Tlapa, Tlapa de Comonfort, 17 de novembro de 2003.

334

Promovendo a Esperança, $8^{\circ}$ Aniversario, Um Projeto Integral, Comissão da Pastoral Social da Diocese de Tlapa, Gro., outubro, 2003. 
que se buscou a intervenção de várias instâncias governativas, para que procedessem a diversas polícias estaduais e federais, assim como elementos do exercito. A solução não chegou: "Em lugar de proteger vinham submeter e provocar." 35

Com as assembleias comunitárias "a gente tomou valor para denunciar e buscar solução no mesmo povo em seus usos e costumes, em sua cultura" ${ }^{36}$, pois o governo não lhes dava solução alguma.

Assim as coisas, em Santa Cruz El Rincón, do Município de Malinaltepec, 15 de outubro de 1995, em uma Assembleia Comunitária com a Participação de trinta e oito comunidades, se funda a Polícia Comunitária. "Seu objetivo fundamental era resgatar a segurança que estava sequestrada nas mãos dos delinquentes." ${ }^{37}$ Seus membros se chamam "policiais comunitários", porque surgem das próprias comunidades e lhe dão seus serviços sem receber salário; não atuam com critérios econômicos, senão que os guia a consciência de que é um serviço para a vida do povo.

Em um principio, os policiais comunitários depois de capturar ao delinqüente o entregavam à Agência do Ministério Público. Contido, de pouco servia; os autores de delitos, as planejavam, ou melhor dito corrompiam as autoridades para ser liberados rápido e reapareciam reincidindo em seus atos delitivos e burlando assim as autoridades comunitárias. Então a Assembléia Comunitária buscou solução a esta problemática e decidiram recorrer a sua história como povo, concretamente ao modo em que seus antepassados administravam a justiça. As comunidades deviam recuperar a sabedoria do passado para atualizar-la e aplicarla no contexto atual; se chegou a conclusão de que os usos e costumes de seus antepassados haviam funcionado e que constituíam uma alternativa que teria que retornar.

Assim 22 de fevereiro de 1998 na comunidade de O Potrerillo Cuapinole do Município de San Luis Acatlan com a participação das autoridades das comunidades que

\begin{tabular}{|c|c|}
\hline \multicolumn{2}{|c|}{35} \\
\hline & Ibídem \\
\hline \multirow[t]{2}{*}{33} & \\
\hline & bídem \\
\hline \multirow[t]{2}{*}{33} & \\
\hline & Ibídem \\
\hline
\end{tabular}




\section{A EXPERIÊNCIA INDÍGENA MEXICANA}

\section{2}

integram a Coordenação, policiais comunitários, comissários municipais, comissários de bens comuns e de organizações sociais que impulsionaram este processo, em Assembleia Comunitária se decide não dividir a justiça em base à tradição dos ancestrais, e para eles se constitui a Coordenação Regional de Autoridades Comunitárias (CRAC). ${ }^{38}$

Se adota como sanção para os que tenham cometido delitos a Reeducação.

Esta Experiência Comunitária de Seguridade, Não divisão da Justiça e Reeducação baseia suas atuações em duas virtudes constitutivas do jurídico, que a concepção moderna do Direito, identificando a este com a lei, esqueceu; me refiro à equidade e a prudência. A justiça aplicada ao caso concreto e a necessidade cambiante que requer soluções adequadas, guiam a aplicação de usos e costumes. No fundo está como expressa Martínez Sifuentes “ a tradição de justiça e respeito à vida que possui a imensa maioria dos povos indígenas do país. ${ }^{\circledR 39}$

Como uma mostra da eficácia do exercito desta justiça comunitária, está o feito recente de que a CRAC, com respaldo de assembleias concordou reeducar mediante usos e costumes a quatro indígenas e um mestiço detidos com 600 kilogramas de maconha e concordou também incinerar los 33 pacotes que continham a droga ${ }^{40}$ Demonstrando assim que pode combater-se de outro modo o narcotráfico.

\section{Guarda Comunitária da Comunidade de Santa María de Ostula}

A comunidade de Santa María de Ostula, da costa de Michoacán, por assembleia geral, acordou "a recuperação pela via dos feitos das terras que lhes pertencem" ${ }^{41}$, lavando a cabo sua ação reivindicatória de 29 de junho de 2009, ocupando mais de mil hectares de

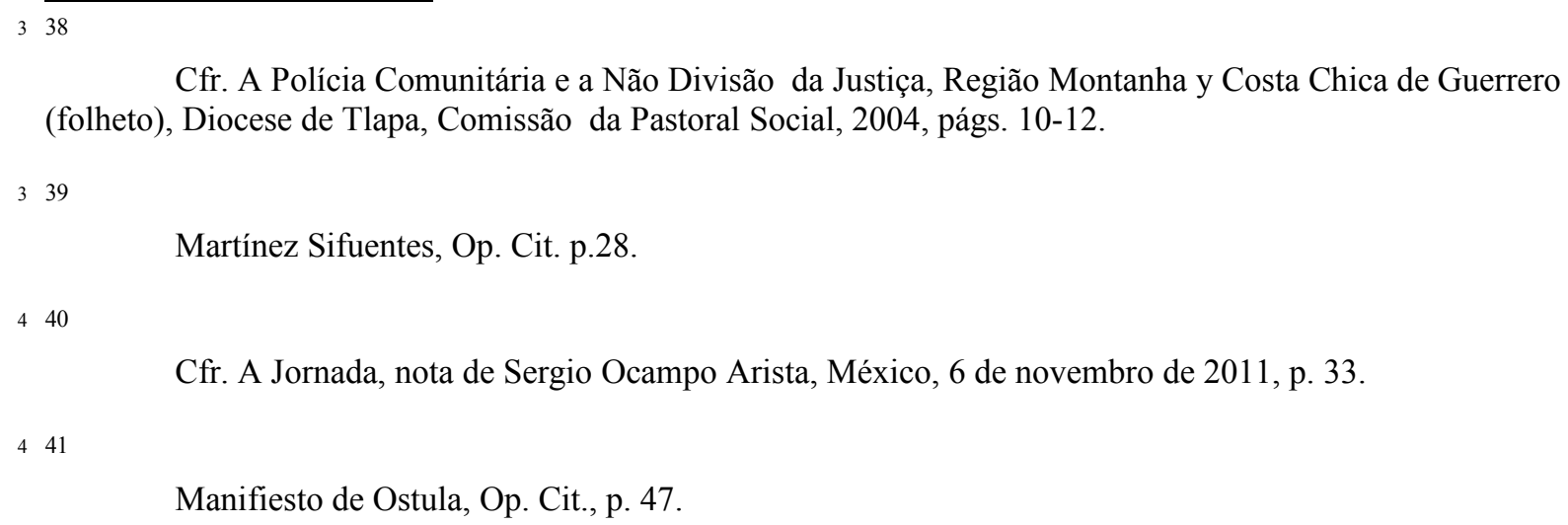

Cfr. A Polícia Comunitária e a Não Divisão da Justiça, Região Montanha y Costa Chica de Guerrero (folheto), Diocese de Tlapa, Comissão da Pastoral Social, 2004, págs. 10-12.

Martínez Sifuentes, Op. Cit. p.28.

440

Cfr. A Jornada, nota de Sergio Ocampo Arista, México, 6 de novembro de 2011, p. 33.

$4 \quad 41$

Manifiesto de Ostula, Op. Cit., p. 47. 
terras, montes e praias que durante mais de quarenta anos estiveram em mãos de pequenos proprietários de La Placita; a essas terras lhes nomearam Xayakalan. ${ }^{42}$

A recuperação dessas terras e a conservação das mesmas, há sido graças à Guarda ou Polícia Comunitária formada pela própria gente de Ostula, e das comunidades nahuas irmãs de Coire y Pómaro. Neste caso a guarda comum não enfrenta à delinquência organizada, sua tarefa é cuidar do território recuperado pela comunidade.

O sistema de segurança do Estado - federal, estadual e municipal - está ausente, é omisso. A comunidade, por essa razão, toma em suas mãos sua própria segurança. Se trata de exercício de autonomia e de uma juridicidade que nasce do povo.

Esse exercício de autonomia, contudo, não exime ao Estado de responsabilidade por não ter cuidado aos lideres da comunidade de Ostula, os quais tem sido assassinados sistematicamente, como don Trinidad de la Cruz Crisóforo, integrante do Movimento pela Paz com Justiça e Dignidade, que foi eliminado em 6 de dezembro de $2011 .^{43}$

\section{Polícia Comunitária de Cherán}

Em San Francisco Cherán, na meseta purépecha, lenhadores como parte do crime organizado ou apoiado por este, "tem devastado aproximadamente 20 mil hectares de bosque em sinal inequívoco de que o Estado com seus três poderes e em seus três níveis, tem sido omisso, por dizer de menos, em brindar a seguridade frente ao saque de um recurso tão apreciado." 44

Ante semelhante despojo e ausência de Estado, agoniados pela delinquência, os membros da comunidade de Cherán decidiram tomar o controle da segurança e dos acessos a

\footnotetext{
$4 \overline{42}$

Cfr. “YYa te cargó la chingada!”, reportagem não assinado por motivos de segurança, Processo, No. 1832, México, 11 de novembro de 2011, págs. 22-24.

$4 \quad 43$

Ibidem.

$4 \quad 44$

Magdalena Gómez, “Cherán: opacidade do Estado e razão de comunidade”, em La Jornada, México, 24 de maio de 2011 .
} 


\section{A EXPERIENNCIA INDÍGENA MEXICANA}

\section{4}

seus território, a partir de 15 de abril de $2011 .{ }^{45}$ Organizaram uma polícia comunitária, como grupo de autodefesa, suplantando à polícia municipal.

Se trata, também, de um exercito de autonomia e de produção jurídica. No caso de Cherán além de organizar normalmente a autodefesa, já que participa toda a comunidade, se estabeleceu normas contra o alcoolismo. Estas políticas e essas normatividade tem rendido frutos, pois há diminuído consideravelmente a delinquência interna, a desmatamento e o consumo de álcool.

Esse exercício de autonomia, com a autodefesa, tem fortalecido os laços comunitários; há feito crescer a solidariedade. Escutei testemunhas manifestando que a gente se fortalece juntando-se na rua para rezar e comer. "Entre as pedras que servem de prevenção - disse uma reportagem -, os habitantes de Cherán levantaram uma bandeira mexicana. As mulheres fazem torrillas, cozinham feijão, arroz, corundas e tamales." ${ }^{46}$

A comunidade de Cherán se negou a participar nas eleições gerais para renovar autoridades, que se celebraram nos fins de 2011 no Estado de Michoacán. Em exercício de sua autonomia e de uma autêntica democracia, organizou suas próprias eleições nomeadas por seu próprio Direito, por seus usos e costumes, em janeiro de 2012. Assim elegeu as suas autoridades comunitárias. O próprio Instituto Eleitoral do Estado de Michoacán reconheceu a validade da eleição. ${ }^{47}$

Nos últimos dias - meados de abril de 2012 - a violência se recrudesceu em Cherán. Em 18 de abril oito populares do município de Cherán foram assassinados; dois deles executados pelas costas no local conhecido como O Porto; y os seis restantes vitimas de emboscada em outro local do bosque. ${ }^{48} \mathrm{O}$ governo do Estado de Michoacán, querendo eludir 445

“Armam em Cherán ‘exercito’ de civis”, nota de Adán García, em Reforma, 4 de maio de 2011.

$4 \quad 46$

"Em Cherán, a ponto de gritar 'às armas", nota de Francisco Castellanos e José Gil Olmos, em Processo 1803, México, 22 de maio de 2011, p. 24.

$4 \quad 47$

Cfr. "Cherán estréia democracia”, nota de Marcela Turati, em Processo No. 1839, México, 29 de janeiro de 2012, págs. 27-29.

$4 \quad 48$

Cfr. "Luto em Cherán: 'Enfrentamento não foi”, nota de Francisco Castellanos em Processo No. 1851, México, 22 de abril de 2012, págs. 30-33; “Revivem em Cherán 'guerra’ pelo bosque”, nota de Adán García, em 
responsabilidade, explica os feitos como "enfrentamentos" entre os habitantes das comunidades. O Conselho Maior de Governo Comunitário de Cherán, nega que tenha havido "enfrentamento", e afirmam:

“Em Cherán não somos assassinos! Temos dado diversas mostras de que se tem solicitado a intervenção das autoridades federais para proteção de nosso

recurso florestal, incluso contra uma corrente majoritária que se tem pensado em uma confrontação direta com a comunidade agressora." ${ }^{49}$

Podemos dizer com Adela Damián: “Graças Cherán por defender a vida de todos nós, por defender a Nana Echeri, por defender os bosques, por defender a água, por defender a vida." $" 50$

\section{Para terminar.}

Das experiências que temos analisado, e de outras, como é o caso de San Juan Copala, dos triquis, em Oaxaca, se desprende que o pluralismo jurídico produzido e praticado por povos e comunidades indígenas do México, nos últimos anos, é um Direito a margem do sistema jurídico estatal que os exclui e os criminaliza, por ser legalidade de injustiça. $\mathrm{O}$ Direito que nasce de povos e comunidades, em troca, apoia sua luta pela vida, com justiça e dignidade.

Artigo recebido em 05 de maio de 2012 e aceito em 22 de junho de 2012.

Reforma, 20 de abril de 2012.

449

“Luto en Cherán...”, Op. Cit., p. 31.

550

Adela Damián Barajas (Janintzarani), Reflexiones (Dedicado a la heroica lucha de Cherán), en Christus No. 789, México, marzo-abril, 2012, en la contraportada. 